\title{
Dynamic Mechanical Properties and Constitutive Model of Selective Laser Melting 316L Stainless Steel at Different Scanning Speeds
}

\section{Yongsheng Ge}

Anhui Jianzhu University

Jingfa Lei ( $\nabla$ rain78828@163.com )

Anhui Jianzhu University

Tao Liu

Anhui Jianzhu University

Wei Bai

Anhui Jianzhu University

\section{Research Article}

Keywords: 316L stainless steel, Selective laser melting, Mechanical properties, Constitutive module

Posted Date: August 26th, 2021

DOI: https://doi.org/10.21203/rs.3.rs-835137/v1

License: (c) (i) This work is licensed under a Creative Commons Attribution 4.0 International License. Read Full License 


\title{
Dynamic mechanical properties and constitutive model of selective laser melting 316L stainless steel at different scanning speeds
}

\author{
Yongsheng $\mathrm{Ge}^{1}$, Jingfa Lei ${ }^{1,2 *}$, Tao $\mathrm{Liu}^{1,2}$,Wei Bai ${ }^{1}$ \\ ${ }^{1}$ School of Mechanical and Electrical Engineering, Anhui Jianzhu University, Hefei, Anhui 230601, China \\ ${ }^{2}$ Anhui Education Department Key Laboratory of Intelligent Manufacturing of Construction Machinery, Hefei, Anhui \\ 230601, China
}

\begin{abstract}
A 316L stainless steel material is widely used in the design of impact-resistant structures. Using selective laser melting (SLM) technology to form 316L stainless steel to study its mechanical behavior under dynamic loading is vital to improve the service performance of this product. This study investigates the dynamic compression mechanical properties and the constitutive models of $316 \mathrm{~L}$ stainless steel specimens formed at different scanning speeds. The quasi-static and dynamic compression mechanical properties of SLM316L stainless steel specimens formed at four scanning speeds were tested using an electro-hydraulic servo experimental system and split Hopkinson pressure bar experimental apparatus. Microstructure observation was used to analyze the differences in the mechanical properties of specimens with different forming parameters. Finally, the modified Johnson-Cook (J-C) constitutive model was established and compared with the experimental data to illustrate the applicability of the modified model in describing the dynamic mechanical properties of SLM3161 stainless steel. In dynamic compression mechanics experiments, the results show that SLM316L stainless steel specimens exhibit typical viscoplastic characteristics and significant strain rate strengthening effects. Furthermore, the scanning speed significantly affects the stacking characteristics of SLM-formed specimens, and the yield strength in axial compression decreases with the loss of stacking characteristics. Finally, the modified J-C model can accurately describe the mechanical properties of SLM3161 stainless steel. This study can provide a theoretical model and methodological support for the design and development of SLM3161 stainless steel.
\end{abstract}

Keywords: 316L stainless steel; Selective laser melting; Mechanical properties; Constitutive module

\section{Introduction}

Selective laser melting (SLM) is one of the typical additive manufacturing (AM) technologies [1,2]. This technology enables the rapid preparation of complex structural parts and has the advantages of a short forming cycle and high material utilization rate [3-5]. It has a broad application prospect in the field of metal parts manufacturing [6-8]. 316L stainless steel is a common metal material formed by SLM technology, which has good mechanical properties and is widely used in the aerospace, automotive industry, and other fields. Formed SLM316L stainless steel components are often used in the design of compressive structures $[9,10]$. However, the dynamic mechanical properties of SLM316L stainless steel developed by different process parameters vary greatly. Therefore, clarifying

* Corresponding author:

Address: 292 Ziyun Ave, Hefei, Anhui 230601, China.

E-mail: rain78828@163.com. 
the dynamic mechanical properties of slm3161 stainless steel with varying parameters of the process, establishing the constitutive model for ensuring the service safety of the material, and realizing the optimal design of the product are of great significance.

In recent years, many researchers have made extensive studies on the microstructure and mechanical properties of SLM stainless steel materials around process parameters, such as laser power, scanning speed, and powder feeding rate. For example, optimizing the laser energy density can enhance the intensity of SUS316L material [11], and choosing a reasonable scanning speed can improve the surface quality and increase the hardness of $316 \mathrm{~L}$ material [12]. Furthermore, the forming angle and scanning strategy also significantly affect the microstructure and tensile strength of SLM316L material $[13,14]$. Some scholars have optimized the Johnson-Cook (J-C) model to predict the dynamic mechanical behavior of materials at high strain rates more accurately. Zhou et al. [15] analyzed the stress-strain curve obtained from the SHPB experiment and modified the J-C model of Ti6Al4V based on dislocation stacking theory. Zhu et al. [16] modified the strain rate hardening coefficient in the J-C model by studying the adiabatic heating of the specimen in the SHPB experiment. Seo et al. [17] carried out a wide strain rate tensile test on 304/316 stainless steel. They improved the J-C model by combining the relationship between plastic strain and strain rate to reduce the error between the model and experimental data at different strain levels.

Given the existing literature, studies on the dynamic compressive mechanical behavior of SLM316L stainless steel materials prepared by different forming processes under high strain rates are limited. The present study prepared four kinds of SLM316L stainless steel samples at different scanning speeds and tested their quasi-static and dynamic compression mechanical properties. The microstructure of $\operatorname{sim} 3161$ stainless steel formed by different processes was analyzed to clarify the micro mechanism of mechanical properties difference. Finally, the J-C model of the material is established to describe its quasi-static and dynamic compression mechanical behavior, and the applicability of the constitutive model is illustrated by comparing it with the experimental data. This study can provide a theoretical basis for achieving the ideal mechanical properties of slm3161 stainless steel under impact load.

\section{Preparation of experimental materials and samples}

This study used the TB-SLM100 laser-selective melting equipment as the forming device equipped with a single-mode fiber laser IPG500W with a wavelength of $1064 \mathrm{~nm}$ and its spot output in a circular pattern with a diameter of $70 \mu \mathrm{m}$. The experiments used spherical 316L stainless steel powder prepared by aerosolization method as the raw material. Figure 1 shows the powder's microscopic morphology. Most of the particles are spherical, and a few are irregularly shaped, indicating good sphericity. The particle size distribution was $15-53 \mu \mathrm{m}$. Table 1 shows its chemical composition. 


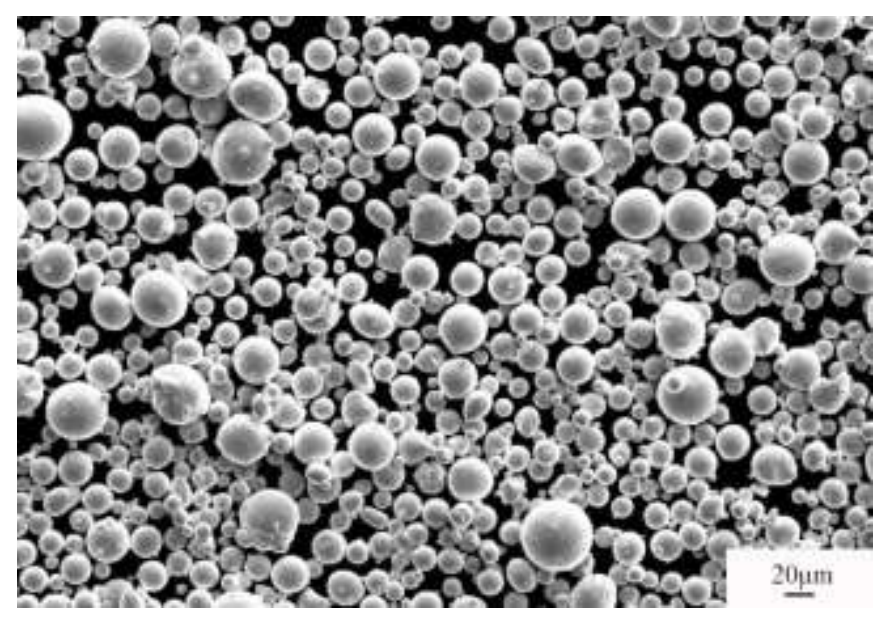

Fig 1. Microstructure of SLM316L stainless steel powder

Table 1 Chemical components of 316L stainless powder

\begin{tabular}{cccccccccc}
\hline Composition & $\mathrm{C}$ & $\mathrm{Si}$ & $\mathrm{P}$ & $\mathrm{S}$ & $\mathrm{Mn}$ & $\mathrm{Mo}$ & $\mathrm{Ni}$ & $\mathrm{Cr}$ & $\mathrm{Fe}$ \\
\hline Mass fraction/\% & $\leq 0.03$ & $\leq 1.00$ & $\leq 0.035$ & $\leq 0.03$ & $\leq 2.00$ & $2.00 \sim 3.00$ & 12.2 & $16.00 \sim 18.00$ & $\mathrm{Bal}$ \\
\hline
\end{tabular}

In the experiment, the laser power $(180 \mathrm{~W})$, scanning distance $(0.1 \mathrm{~mm})$, and powder thickness $(50 \mu \mathrm{m})$ were controlled unchanged. Under the scanning speed of $350,650,950$, and $1250 \mathrm{~mm} / \mathrm{s}$, the $\Phi 12 \times 5 \mathrm{~mm}$ cylindrical specimen was prepared for the quasi-static mechanical test, and the $\Phi 12 \times 15 \mathrm{~mm}$ cylindrical specimen was prepared for the dynamic mechanical test. Figure 2 shows the real object of the formed part.

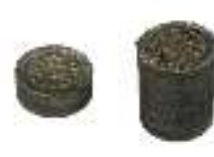

(a) $350 \mathrm{~mm} / \mathrm{s}$

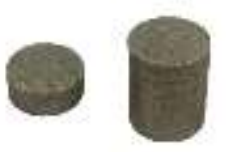

(b) $650 \mathrm{~mm} / \mathrm{s}$

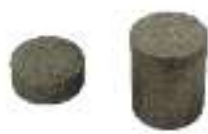

(c) $950 \mathrm{~mm} / \mathrm{s}$

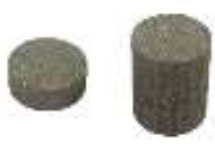

(d) $1250 \mathrm{~mm} / \mathrm{s}$

Fig 2. Physical drawings of SLM316l stainless steel with different process parameters

\section{Mechanical properties analysis of quasi-static and dynamic compression}

\subsection{Quasi-static mechanical property test}

Quasi-static compression experiments were performed on SLM316L stainless steel specimens $\left(\varphi 12 \times 15 \mathrm{~mm}^{2}\right)$ at room temperature $\left(25^{\circ} \mathrm{C}\right)$ by using the MTS Landmark® 370.5 electrohydraulic servo experimental system (Figure 3). The specimens were fixed at the center of the base, and lubricant was applied to the specimens' ends to reduce the end friction between the specimens and the chucks. The accuracy of the experimental results is ensured by adding an external tensiometer to the equipment. Following specimen size, the chunk loading speed was set to $0.015 \mathrm{~mm} / \mathrm{s}$, and the control strain rate was $0.001 \mathrm{~s}^{-1}$. Each state specimen had three sets of experiments. 


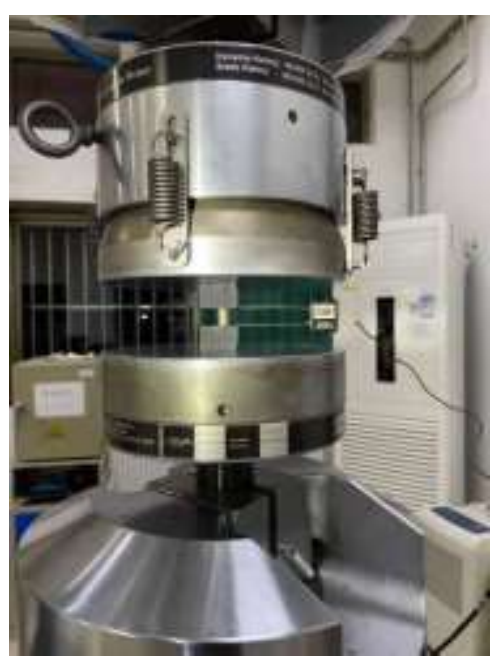

Fig 3. Quasi-static compression experiments

\subsection{Dynamic mechanical property test}

An SHPB experimental apparatus was used to perform dynamic compression mechanical experiments at high strain rates. The composition of the apparatus, which consists of a loading device (air gun), a compression bar device (impact, incidence, and transfer bars), a data acquisition system, and a damping absorber, is presented in Figure 4. The material of each bar was low alloy steel with an elastic modulus of $210 \mathrm{GPa}$, a density of $7.83 \mathrm{~g} / \mathrm{cm} 3$, and a wave speed of approximately $5100 \mathrm{~m} / \mathrm{s}$.

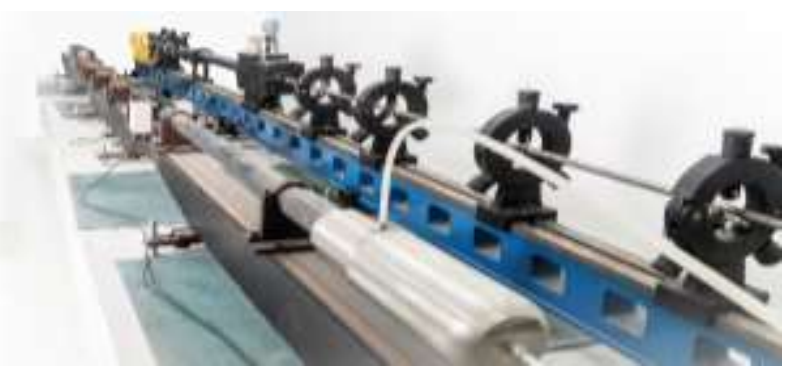

(a) Physical drawing of SHPB experimental device

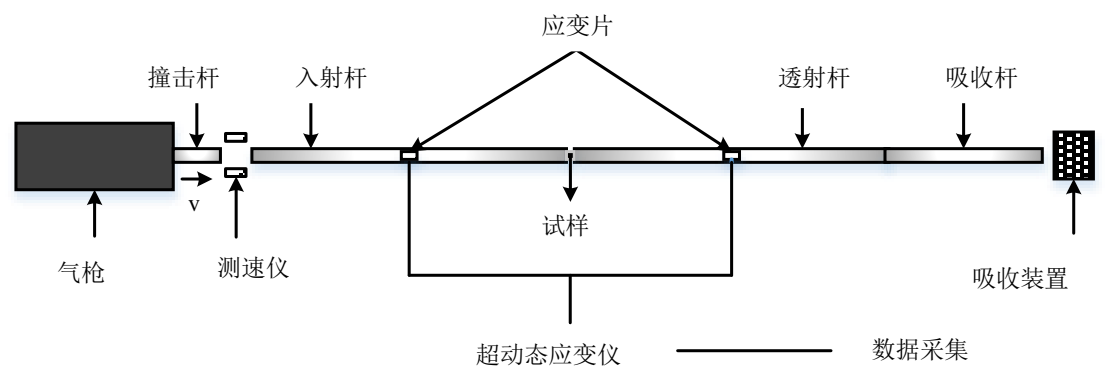

(b) Schematic diagram of SHPB experimental device

Fig 4. SHPB experimental device

The SLM 316L stainless steel cylindrical specimen $(\varphi 12 \times 5 \mathrm{~mm} 2)$ was clamped between the incident bar and the transfer bar, and lubricant was applied to the contact area at both ends of the specimen to reduce the end-face friction effect. The striking bar was pushed by the air gun into the incident bar, generating a transient pulsed incident stress wave $\sigma_{\mathrm{i}}$, which was transmitted through the incident bar to the interface between the specimen and the incident bar. 
In this process, part of the stress wave was reflected onto the incident bar, forming the reflected stress wave $\sigma_{\mathrm{r}}$. The rest was transmitted into the transmission bar, forming the transmitted stress wave $\sigma_{t}$. The three stress waves generated elastic strains $\varepsilon_{\mathrm{i}}, \varepsilon_{\mathrm{r}}$, and $\varepsilon_{\mathrm{t}}$ in the incident and transmitted rods. Then, the strain rate $\&(t)$, strain $\varepsilon(t)$, and stress $\sigma(t)$ of the material were obtained following the principle of the linear superposition of 1D stress waves, as shown in Equation(1), and transformed into stress-strain curves [18,19].

$$
\left\{\begin{array}{l}
\varepsilon(t)=\frac{\mathrm{c}_{0}}{\mathrm{~L}_{0}} \int_{0}^{t}\left(\varepsilon_{i}-\varepsilon_{r}-\varepsilon_{t}\right) \mathrm{d} t \\
\&(t)=\frac{\mathrm{c}_{0}}{\mathrm{~L}_{0}}\left(\varepsilon_{i}-\varepsilon_{r}-\varepsilon_{t}\right) \\
\sigma(t)=\frac{\mathrm{AE}}{\mathrm{A}_{0}}\left(\varepsilon_{i}+\varepsilon_{r}+\varepsilon_{t}\right)
\end{array}\right.
$$

In Formula (1), $\mathrm{c}_{0}, \mathrm{E}$ and $\mathrm{A}$ are the elastic wave velocity, elastic modulus, and cross-sectional area of the compression bar, respectively; $\mathrm{L}_{0}$ and $\mathrm{A}_{0}$ are the original length and cross-sectional area of the specimen, respectively.

\section{Analysis of static and dynamic mechanical properties}

Figure 5 shows the stress-strain curves of 316L stainless steel samples with four scanning speed process parameters in quasi-static $\left(0.001 \mathrm{~s}^{-1}\right)$ and dynamic $\left(10^{2}-10^{4} \mathrm{~s}^{-1}\right)$ compression mechanical properties tests. The quasi-static and dynamic stress-strain curves are generally similar, which can be roughly divided into elastic and plastic stages, showing the common elastic-plastic characteristics with general metal materials. In the quasi-static curve, when the sample strain is less than 0.02 , the stress increases linearly with the strain, and the elastic modulus remains constant, which is the elastic stage. After entering the plastic stage, no apparent yield phenomenon is observed in the figure because of the joint action of strain strengthening when the material yields. After the yield stage, the specimen enters the stable strain strengthening stage, and the stress value increases continuously with the increase of plastic strain. The material shows noticeable strain strengthening characteristics. In the dynamic stress-strain curve of a high strain rate, the mechanical response is the same as that of a quasi-static state. The linear elastic characteristics and strain hardening phenomenon of the material are apparent. However, the obvious upper yield point and lower yield point can be observed in the dynamic mechanical curve. This phenomenon is more evident with the increase of strain rate. 


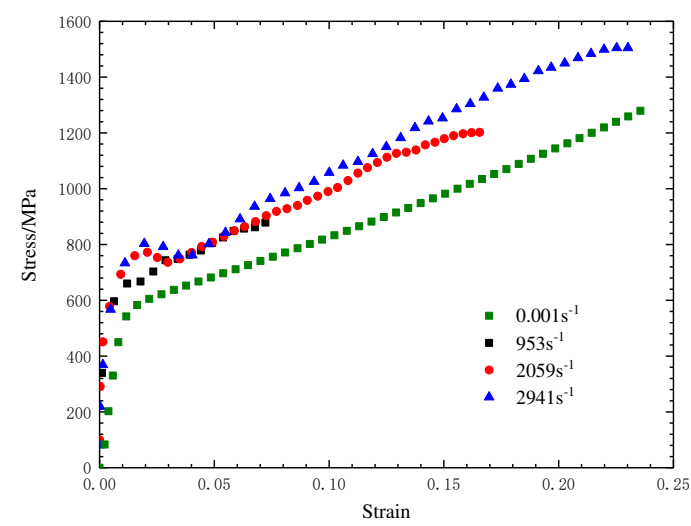

(a) $350 \mathrm{~mm} / \mathrm{s}$

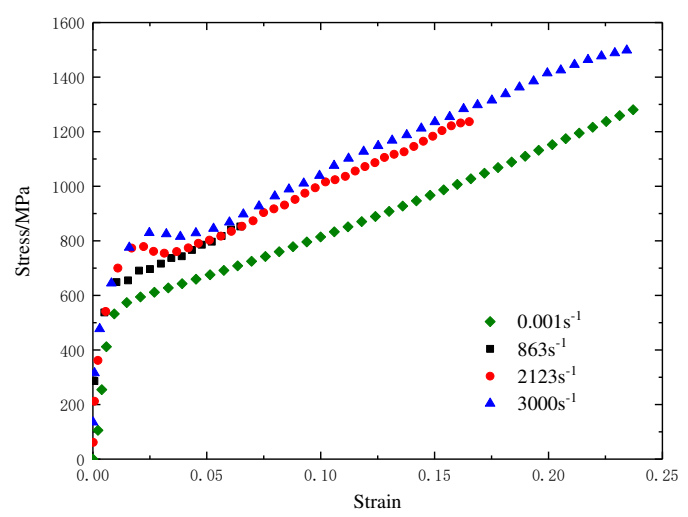

(a) $950 \mathrm{~mm} / \mathrm{s}$ (b) $650 \mathrm{~mm} / \mathrm{s}$

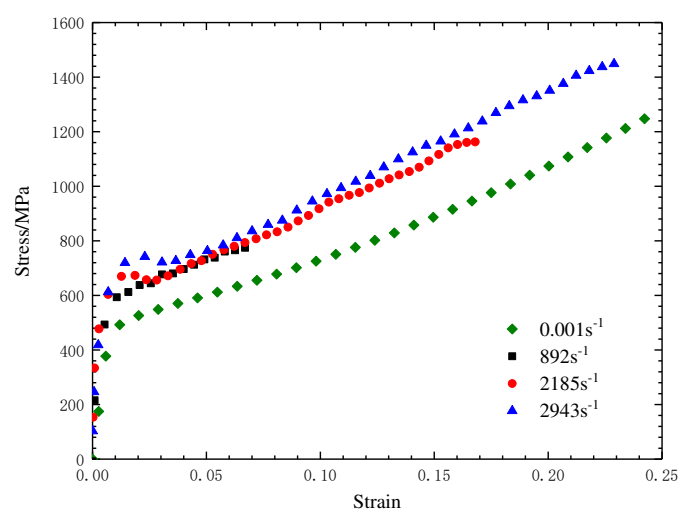

(d) $1250 \mathrm{~mm} / \mathrm{s}$

Fig 5. Quasi-static and dynamic compressive stress-strain curves of specimens with four kinds of process parameters

Comparing the peak yield stress in the high strain rate $\left(10^{2}-10^{4} \mathrm{~s}^{-1}\right)$ and quasi-static $\left(0.001 \mathrm{~s}^{-1}\right)$ stress-strain curves, the specimens show obvious strain rate sensitivity under dynamic loading. When the strain rate increases from 0.001 to $10^{2} \mathrm{~s}^{-1}$, the peak yield strength of $350,650,950$, and $1250 \mathrm{~mm} / \mathrm{s}$ specimens increases by $18.9 \%, 19.1 \%$, $15.5 \%$, and $24.3 \%$, respectively, and the average yield strength increases by $19.45 \%$. The strain rate sensitivity of specimens is noticeable from quasi-static to dynamic loading. However, when the loading strain rate increases from $10^{2}$ to $10^{4} \mathrm{~s}^{-1}$, the peak yield stress does not change much. When the process parameters are $350,650,950$, and 1250 $\mathrm{mm} / \mathrm{s}$, the dynamic yield strength increases by $4.0 \%, 4.8 \%, 6.4 \%$, and $9.9 \%$, respectively, indicating that the strain rate hardening effect is weak when the compression strain rate is within the same order of magnitude. Furthermore, the figure shows that the yield strength of the sample formed at $1250 \mathrm{~mm} / \mathrm{s}$ is significantly lower than that of the sample formed at 350-950 mm/s. Figure 6 shows the peak yield strength of four scanning speed specimens under different loading strain rates. 


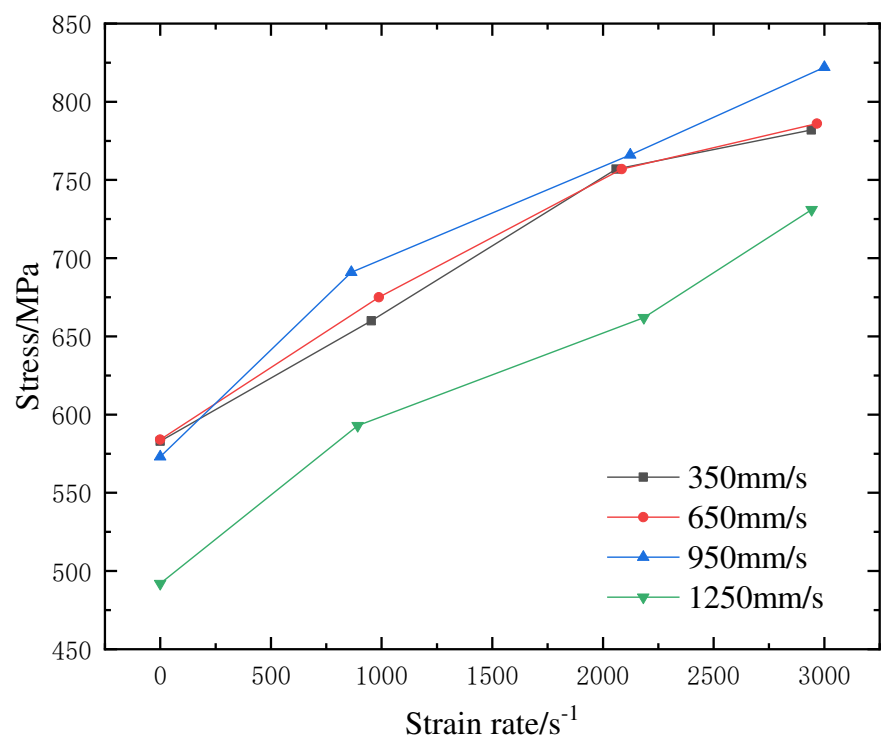

Fig.6 The peak yield strength of four scanning speed specimens under different loading strain rates

\section{Microstructure analysis of samples with different parameters}

The different process samples were ground with sandpaper along the laser scanning plane until the observation surface was flat and then polished mechanically to obtain a bright mirror. The metallographic specimens were etched in aqua regia $(3 \mathrm{ml} \mathrm{HNO3}+1 \mathrm{ml} \mathrm{HCl})$ for $10 \mathrm{~s}$. The microstructure of the specimens was observed by Zeiss evo180 scanning electron microscope. Furthermore, the samples of different processes were cut along the deposition direction, and the same metallographic treatment obtained the cross-section microstructure.

Figure 7 shows the molten pool morphology of samples with different process parameters perpendicular to the laser scanning. Given the Gaussian distribution of laser energy, the highest energy is concentrated in the beam center, and the powder on both sides of the fusion line will be absorbed during scanning [20,21]. The morphology of the molten pool of the samples with various parameters in the figure is fish scale shape distribution, which is because of the stacking feature of the semi arc molten pool formed by layer by layer sintering and solidification of the metal powder after laser melting. By measuring the melt pool width, a difference is observed in the melt pool size formed with different process parameters. The width of the molten pool is approximately $138.00 \mu \mathrm{m}$ at $350 \mathrm{~mm} / \mathrm{s}$. With the increase of scanning speed, the width of the molten pool decreases gradually (107.86 and $98.95 \mu \mathrm{m}$ at 650 and 950 $\mathrm{mm} / \mathrm{s})$. When the scanning speed reaches $1250 \mathrm{~mm} / \mathrm{s}$, no weld pool stacking feature is evident, and cracks and inclusions appear locally. 


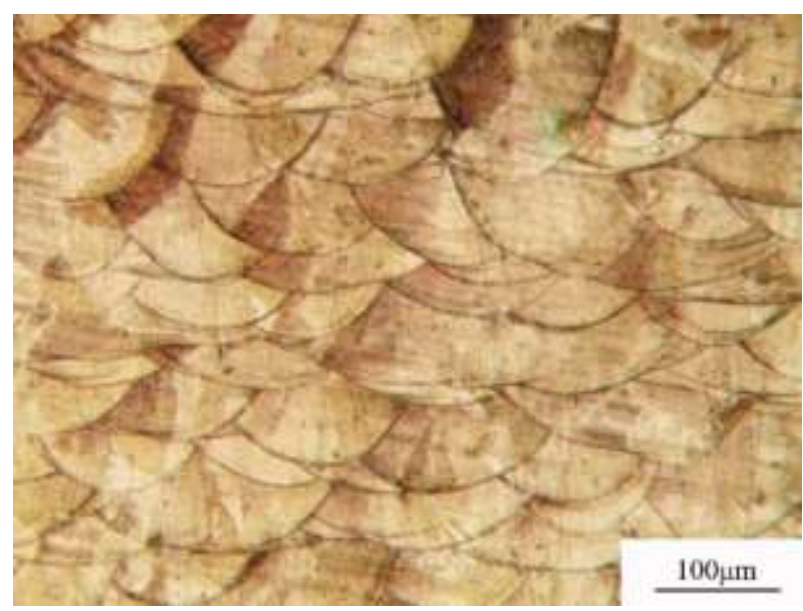

(a) $350 \mathrm{~mm} / \mathrm{s}$

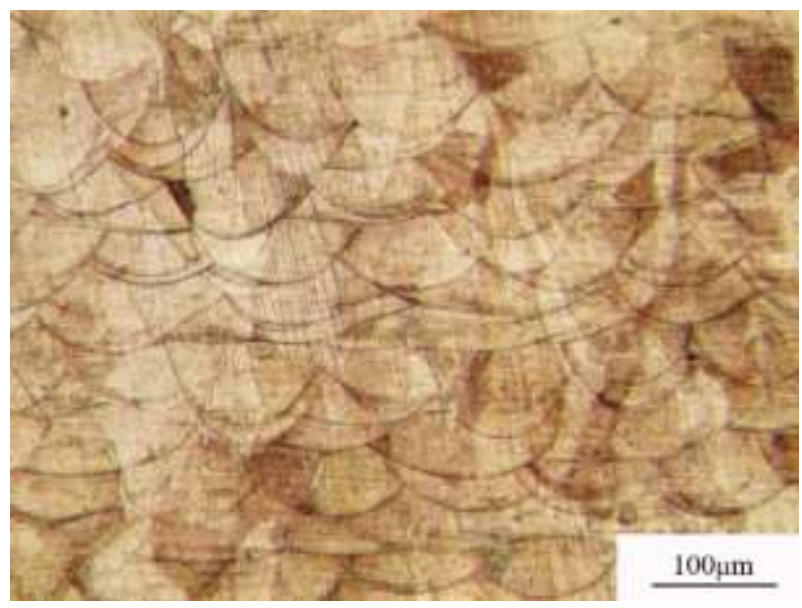

(c) $950 \mathrm{~mm} / \mathrm{s}$

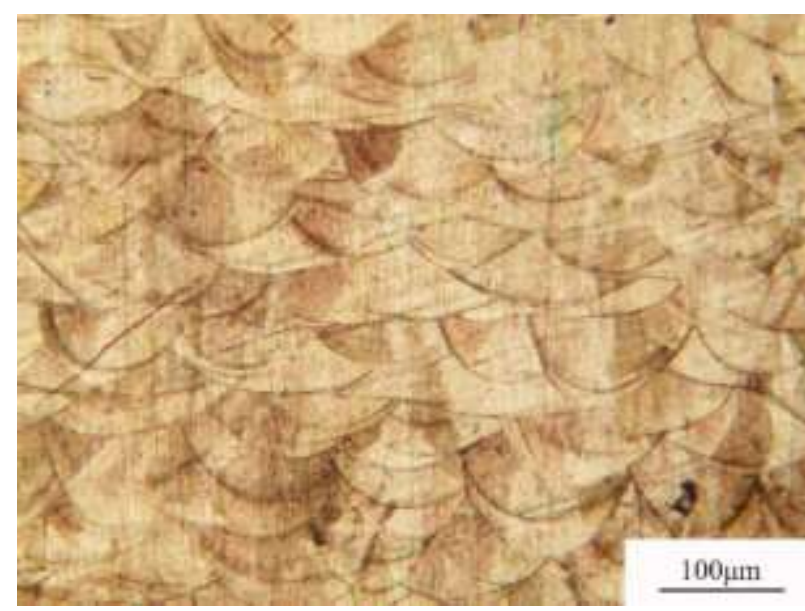

(b) $650 \mathrm{~mm} / \mathrm{s}$

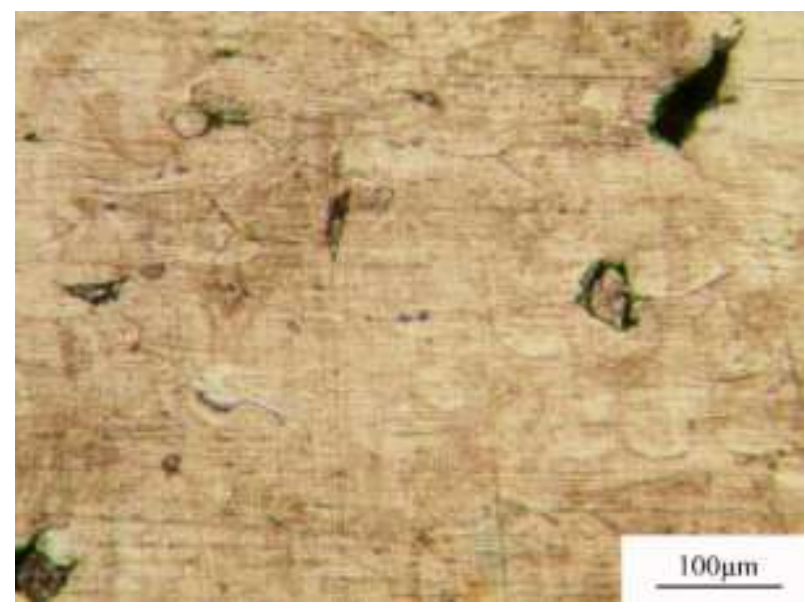

(d) $1250 \mathrm{~mm} / \mathrm{s}$

Fig 7. Morphology of the molten pool perpendicular to the laser scanning plane

The analysis shows that the slower the scanning speed, the larger the heat conduction and radiation range per unit time, the stronger the fluidity of the solution, the larger the size of the molten pool, and the more pronounced the stacking phenomenon of the molten pool. When the scanning speed is excessively high, the metal powder cannot be fully melted, the liquid phase fluidity is poor, the fusion between layers is poor [22], and the unmelted powder inclusions and molten pool defects appear.

Figure 8 shows the micromorphology of samples with different processing parameters parallel to the laser scanning plane. The figure presents the sample's microstructure formed by SLM characterized by typical cellular crystal morphology, mainly composed of equiaxed crystal and columnar crystal. The direction of the fine columnar crystal changes, and the growth direction of different angles appears in the same micro-region. The analysis shows a surface tension gradient on the surface of the molten pool affected by the laser mode. Under the surface tension gradient effect, convection occurs in the molten pool, causing the local deformation of the molten pool, changing the direction of heat dissipation, and affecting the growth orientation of the columnar crystal. Furthermore, the shape of equiaxed grains is close to hexagon, which has the smallest interface energy and grains in a relatively stable equilibrium state. 


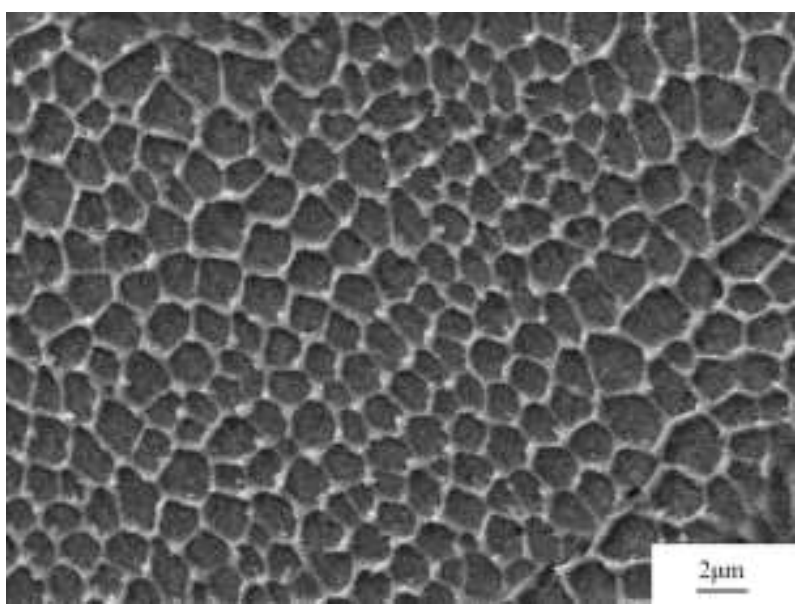

(a) $350 \mathrm{~mm} / \mathrm{s}$

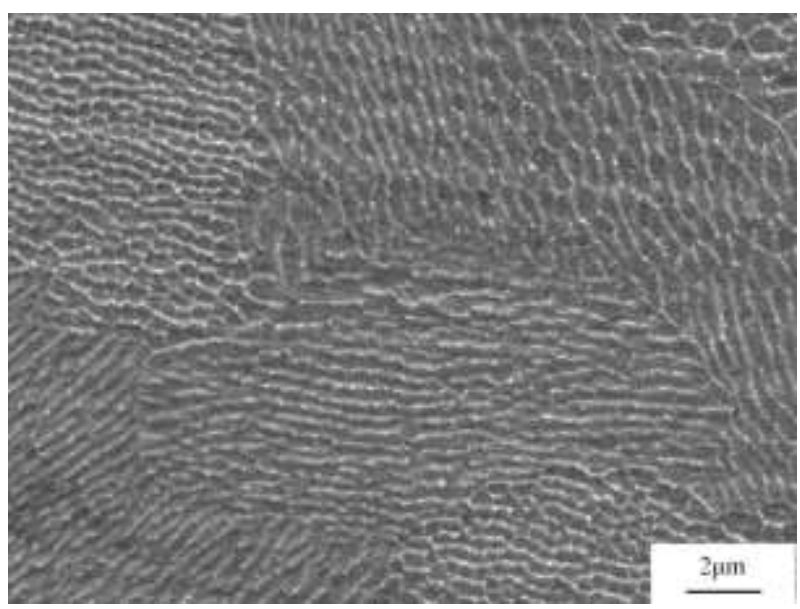

(a) $950 \mathrm{~mm} / \mathrm{s}$

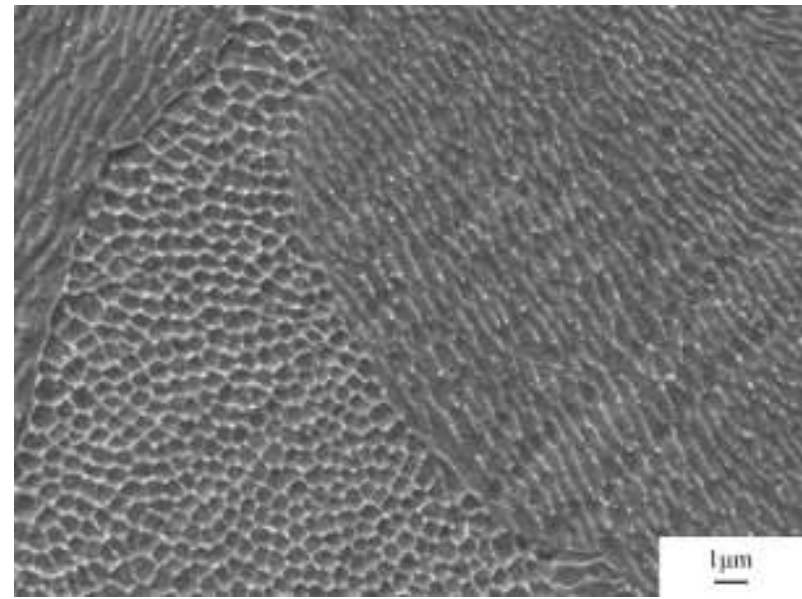

(b) $650 \mathrm{~mm} / \mathrm{s}$

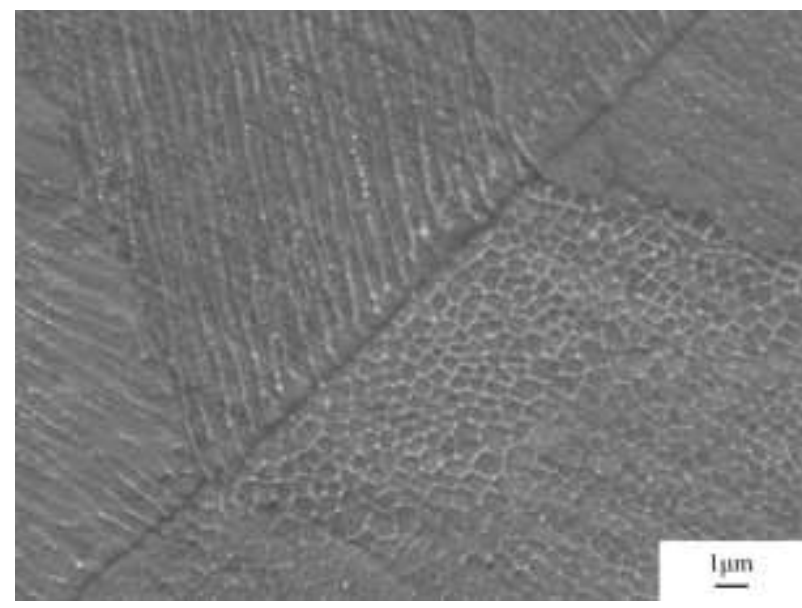

(b) $1250 \mathrm{~mm} / \mathrm{s}$

Fig 8. Micro morphology perpendicular to the laser scanning surface

The microstructure of SLM3161 stainless steel shows a cellular grain structure with a nanometer scale, which is much smaller than that of traditional rolling stainless steel. This structure is related to the SLM forming mode. The melt has a fast solidification rate and large undercooling during the solidification process, making nano-cellular fine structure possible.

Analyzing the mechanical properties of SLM3161 stainless steel samples with four parameters through microstructure observation reveals that the stacking characteristic is the key factor affecting the materials' quasi-static and dynamic compression mechanical properties. When the scanning speed is excessively fast, the fusion between layers is poor, which eventually leads to the quasi-static and dynamic yield strength lower than other forming process samples.

\section{$6 \mathrm{~J}-\mathrm{C}$ constitutive model and dynamic mechanical characterization}

The constitutive relation of the metal material mainly reflects the stress-strain change rule under certain deformation conditions. The J-C constitutive model $[23,24]$ is an elastic-plastic constitutive model, which can describe the dynamic mechanical properties of metal materials well. Given its simple formula and easy parameters, it has been widely used in industrial production. 
The general formula is as follows:

$$
\sigma=\left(\mathrm{A}+\mathrm{B} \varepsilon^{\mathrm{n}}\right)\left[1+\mathrm{C} \ln \left(\frac{\&}{\mathrm{f}}\right)\right]\left[1-\left(\frac{\mathrm{T}-\mathrm{T}_{0}}{\mathrm{~T}_{\mathrm{M}}-\mathrm{T}_{0}}\right)^{\mathrm{m}}\right]
$$

In the formula:

$\sigma$ is the equivalent plastic stress; $\varepsilon$ is the equivalent plastic strain;

$\mathrm{A}, \mathrm{B}$, and $\mathrm{n}$ are the initial yield stress, hardening modulus, and hardening index at the reference strain rate and temperature;

$\&$ and \& are the quasi-static experimental strain rate and the equivalent plastic strain rate, respectively;

$\mathrm{C}$ is the strain rate sensitivity coefficient;

$\mathrm{T}, \mathrm{T}_{0}$, and $\mathrm{TM}$ are the ambient temperature of the sample, room temperature $\left(25^{\circ} \mathrm{C}\right)$, and melting point of the material, respectively, and $\mathrm{m}$ is the temperature sensitivity coefficient.

This experiment's quasi-static and dynamic compression mechanical properties were tested at room temperature $\left(\mathrm{t}=\mathrm{t}_{0}=25^{\circ} \mathrm{C}\right)$. Thus, Formula (2) can be simplified as follows:

$$
\sigma=\left(\mathrm{A}+\mathrm{B} \varepsilon^{\mathrm{n}}\right)\left[1+\mathrm{C} \ln \left(\frac{\&}{\&}\right)\right] .
$$

The parameters A, B, and $\mathrm{n}$ in Formula (3) are calibrated, and the stress-strain curve obtained from quasi-static compression experiment at room temperature $\left(\mathrm{t}=\mathrm{t} 0=25{ }^{\circ} \mathrm{C}\right)$ is used as reference data. Thus, Formula (3) can be reduced as follows:

$$
\sigma=\left(\mathrm{A}+\mathrm{B} \varepsilon^{\mathrm{n}}\right) .
$$

Given the adiabatic temperature rise in dynamic compression, the yield strength $\mathrm{A}$ is obtained from the stress value at the plastic strain of 0.012 according to the quasi-static compression test of different process samples. The hardening coefficient $\mathrm{B}$ and hardening index $\mathrm{n}$ are obtained by fitting the data points in the strengthening stage of the static curve by Formula (4). Table 2 shows the parameters obtained by fitting.

The strain rate sensitivity coefficient $\mathrm{C}$ in Formula (4) is calibrated. The plastic strain is 0 when the dynamic loading reaches yield. In this case, Formula (5) can be simplified as follows:

$$
\sigma=\mathrm{A}\left[1+\mathrm{C} \ln \left(\frac{\&}{\&}\right)\right] .
$$

Using Formula (5) to fit the yield strength of the material under different strain rates, the strain rate sensitivity coefficient $\mathrm{C}$ is obtained. Figure 9 shows the fitting curve. The fitting parameter $\mathrm{C}$ is listed in Table 2. 


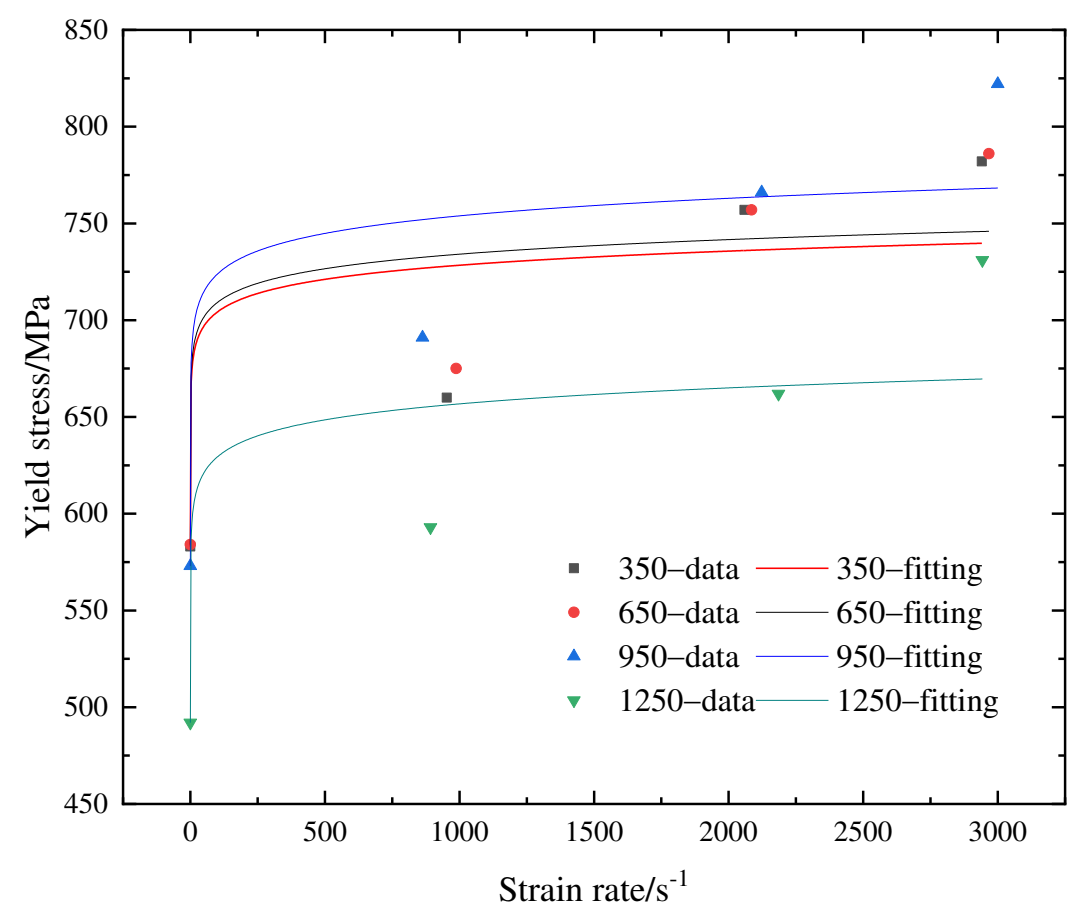

Fig 9. Yield strength and its fitting curve under different strain rates

Table 2. Parameters of the J-C constitutive model

\begin{tabular}{ccccc}
\hline Process parameter (mm/s) & & & \\
parameter & 350 & 650 & 950 & 1250 \\
\hline Yield Strength A/MPa & 583 & 584 & 573 & 492 \\
\hline Hardening modulus B/MPa & 5086 & 4336 & 4554 & 4818 \\
\hline Hardening index n & 1.37 & 1.26 & 1.28 & 1.31 \\
\hline Strain rate sensitivity coefficient C & 0.01805 & 0.01861 & 0.01896 & 0.01812 \\
\hline Material parameter C 1 & $7.23 \mathrm{e}-4$ & $1.37 \mathrm{e}-3$ & $3.3 \mathrm{e}-3$ & $1.16 \mathrm{e}-3$ \\
\hline Material parameter m & 0.77 & 0.69 & 0.60 & 0.75 \\
\hline
\end{tabular}

According to the parameters of the constitutive model, the basic models of $316 \mathrm{~L}$ stainless steel samples under quasi-static and dynamic compression tests can be obtained. Based on the basic model, the quasi-static and dynamic compression experimental data of four process parameters SLM3161 stainless steel are fitted, and the fitting results are shown in Figure 10. 


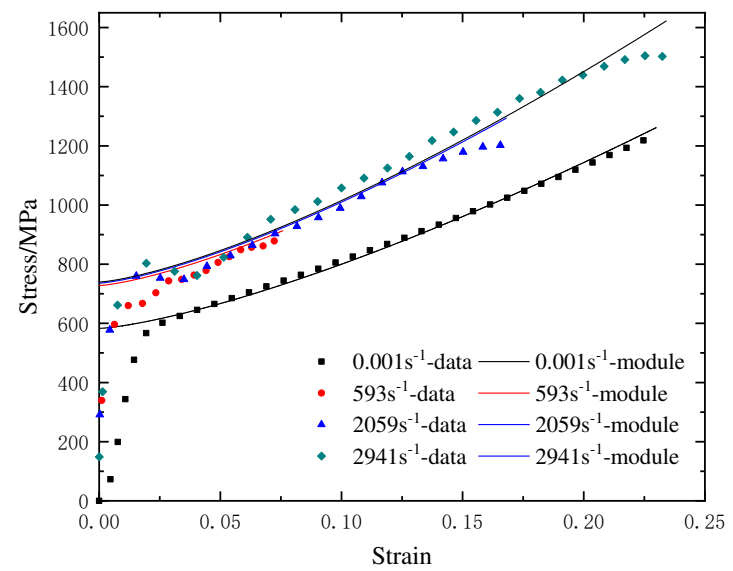

(a) $350 \mathrm{~mm} / \mathrm{s}$

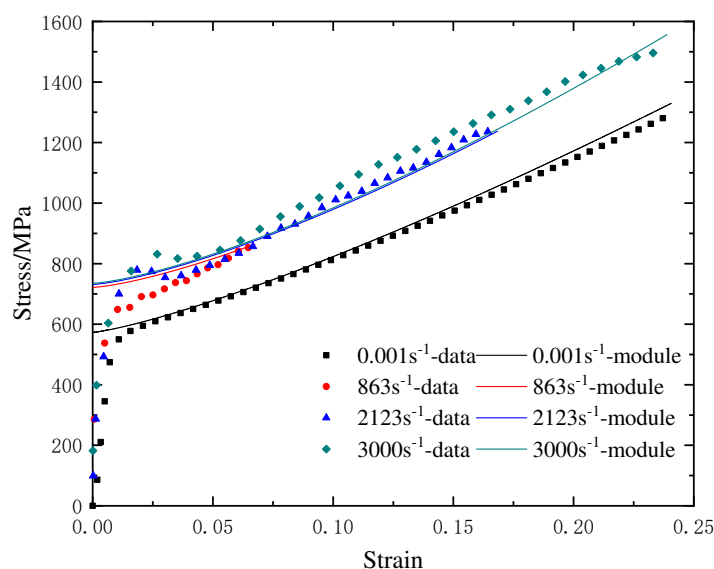

(c) $950 \mathrm{~mm} / \mathrm{s}$

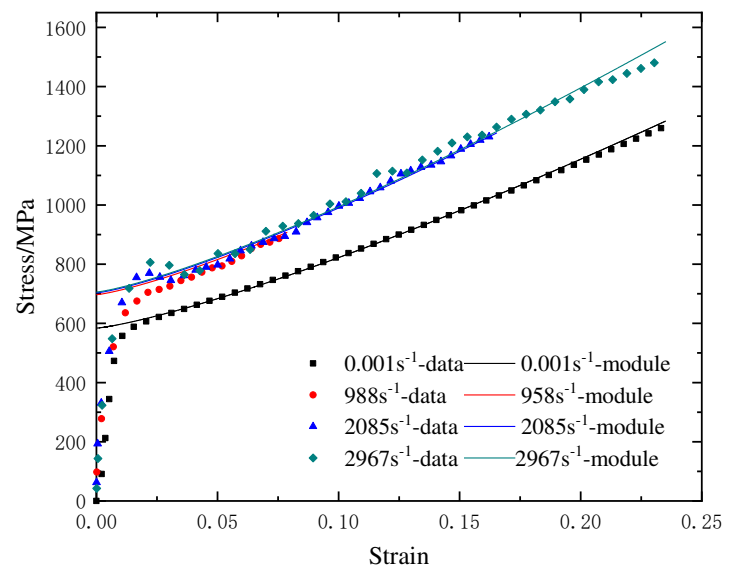

(b) $650 \mathrm{~mm} / \mathrm{s}$

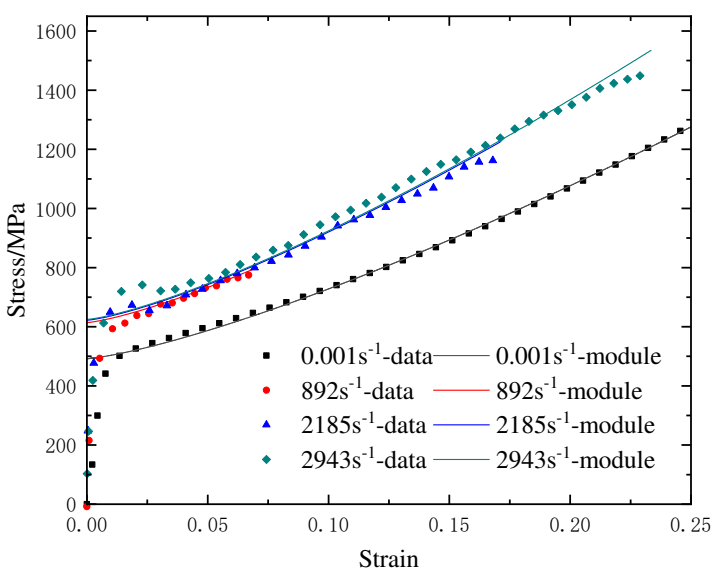

(d) $1250 \mathrm{~mm} / \mathrm{s}$

Fig 10. The fitting curve of stress-strain based on the original J-C model

The fitting diagram shows that the original J-C model can fit the stress-strain curve of slm3161 stainless steel obtained from quasi-static $\left(0.001 \mathrm{~s}^{-1}\right)$ compression test, but apparent differences are found between the fitting curve and the experimental stress-strain curve under high strain rate $\left(10^{2}-10^{4} \mathrm{~s}^{-1}\right)$ dynamic loading. It shows that the parameters $\mathrm{A}, \mathrm{B}$, and $\mathrm{n}$ in the $\mathrm{J}-\mathrm{C}$ model are correct. However, the strain rate sensitivity coefficient $\mathrm{C}$ cannot accurately measure the strain rate sensitivity of materials. In order to better reflect the difference of material strain rate effect in different strain rate range, this paper uses the CS model [25-27] to obtain a relationship between the dynamic stress and strain rate of the material, which is expressed as:

$$
\sigma=\mathrm{A}\left(1+\mathrm{C}_{1} \&^{2}\right)
$$

where $\mathrm{C}$ and $\mathrm{M}$ are material constants that describe the strain rate strengthening properties of the material.

Using formula (6) to fit the yield strength of the material at different strain rates, the parameters $\mathrm{C} 、 \mathrm{~m}$ were obtained. the fitted curves are shown in Figure 11. the fitted parameters are listed in Table 2. 


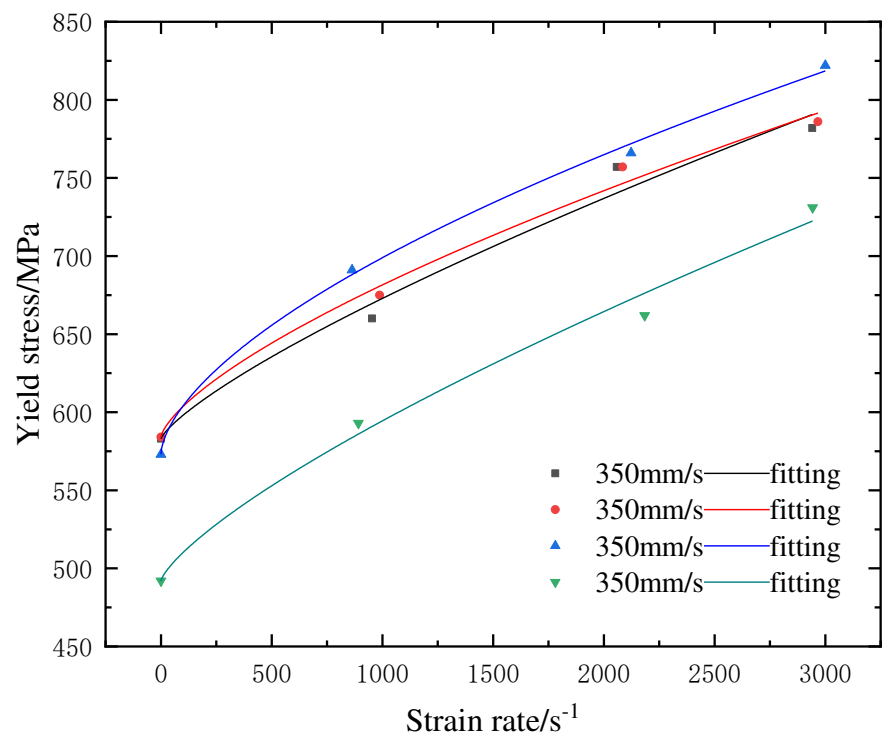

Fig11. The modified fitting curve of parameter $C_{1} 、 m$

According to the modified J-C constitutive model, the quasi-static and dynamic stress-strain curves of SLM3161 stainless steel samples with four process parameters are refitted. Figure 12 shows the fitting results.

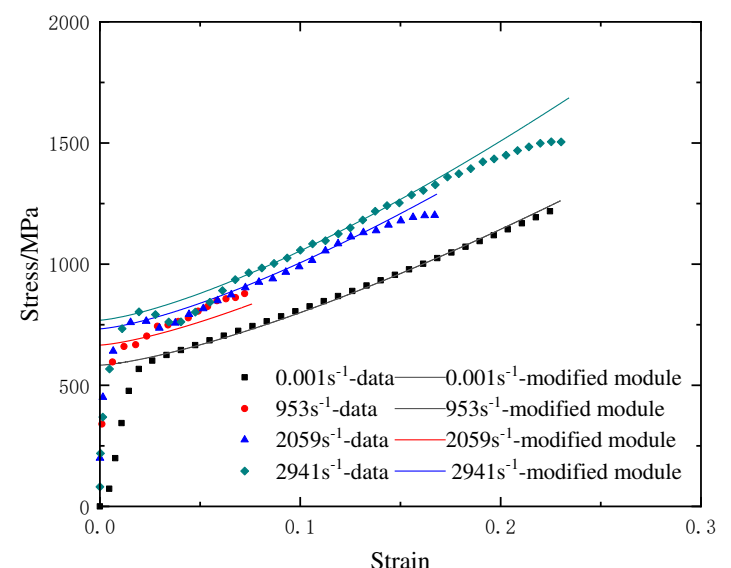

(a) $350 \mathrm{~mm} / \mathrm{s}$

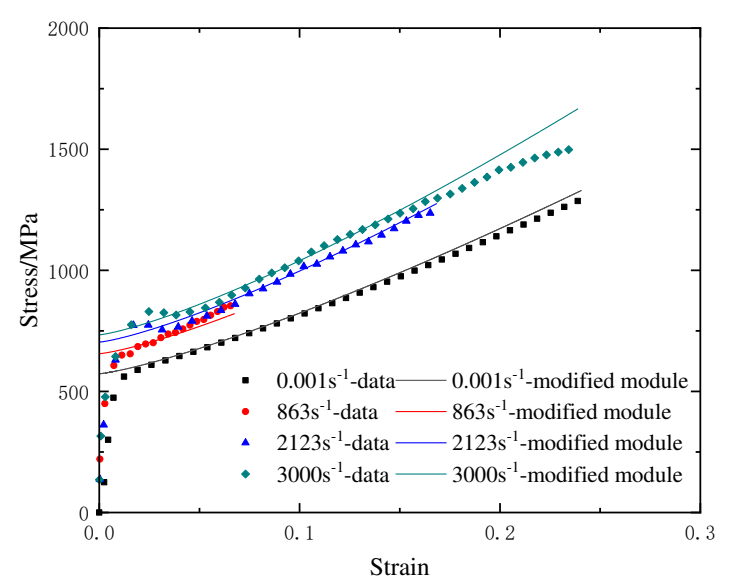

(c) $950 \mathrm{~mm} / \mathrm{s}$

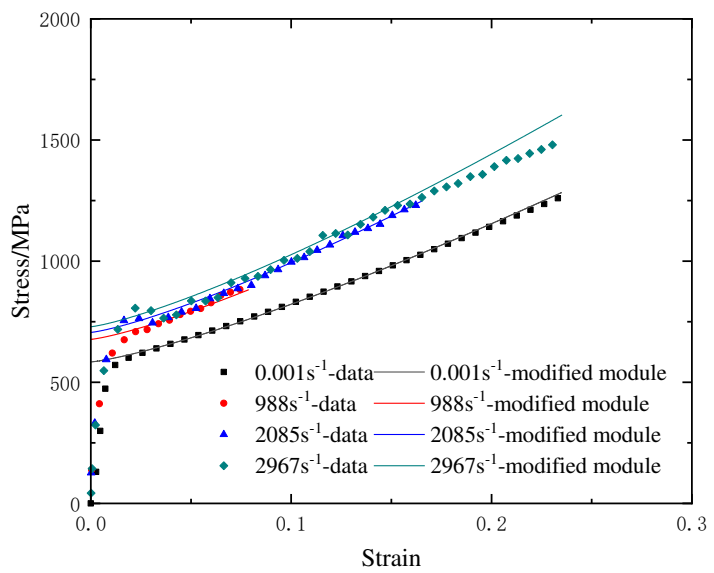

(b) $650 \mathrm{~mm} / \mathrm{s}$

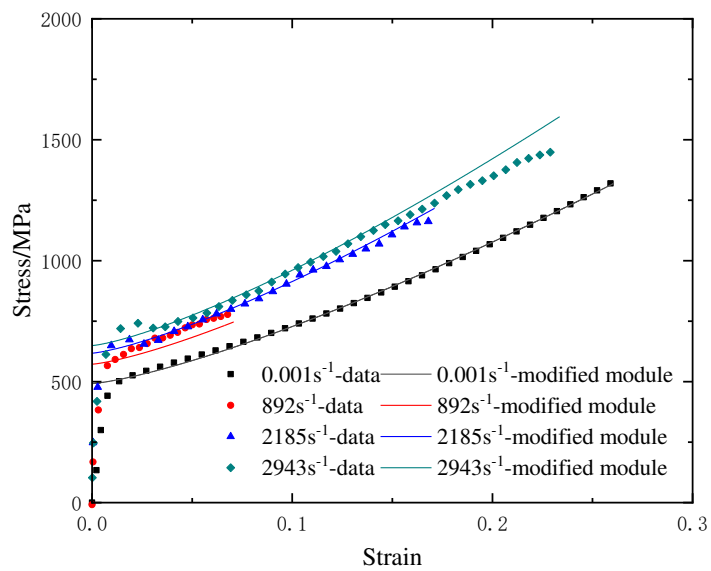

(d) $1250 \mathrm{~mm} / \mathrm{s}$

Fig 12. Stress-strain curve fitting after J-C constitutive modification 
This study compares the fitting curve with the experimental curve. It concludes that the modified J-C constitutive model could better describe the mechanical behavior of SLM3161 stainless steel under quasi-static and dynamic compression tests. Therefore, the modified J-C model has good applicability for predicting the quasi-static and high strain dynamic mechanical properties of SLM3161 stainless steel.

\section{Discussion}

This study presented an experimental method for the design and development of SLM metal materials. The density and surface quality of SLM3161 stainless steel samples formed at different scanning speeds and the mechanical curves of SLM316L stainless steel at low strain rate and high strain rate were measured. This study also analyzed the strain rate sensitivity and strain hardening phenomenon and the mechanical modification mechanism of SLM316L stainless steel at scanning speed from a microscopic angle. Finally, experiments obtained the density, surface roughness, and yield strength of SLM3161 stainless steel and clarified the relationship between the above parameters and SLM scanning speed.

In the design and development of SLM metal materials, the above parameters and characteristics are the key to clarify the mechanical behavior of materials under impact loading and improve the performance of shock-resistant parts in automotive and aviation fields.

\section{Conclusion}

This study obtained SLM3161 stainless steel samples with four scanning speeds $(350,650,950$, and $1250 \mathrm{~mm} / \mathrm{s})$ by changing the laser scanning speed. The surface quality, static, and dynamic mechanical properties of samples with four parameters were studied. The density and surface roughness were measured. The quasi-static $\left(0.001 \mathrm{~s}^{-1}\right)$ and dynamic $\left(10^{2}-10^{4} \mathrm{~s}^{-1}\right)$ compression experiments were carried out. The microstructure was observed, and the elastoplastic constitutive model was established. The analysis of the experimental results revealed the following:

1. The quasi-static and dynamic mechanical behaviors of SLM3161 stainless steel samples with four scanning speeds show typical elastic-plastic characteristics. The material displays an apparent strain rate strengthening phenomenon at a high strain rate. Furthermore, through the microstructure analysis of the four samples, the sample's stacking feature is the primary factor affecting its mechanical properties. Thus, when the scanning speed reaches 1250 $\mathrm{mm} / \mathrm{s}$, the yield strength of the sample is lower than that of the other parameter samples because of the stacking feature's disappearance.

2. The J-C constitutive model established in this study can accurately describe the mechanical behavior of SLM3161 stainless steel under dynamic load. This study fitted the quasi-static and dynamic stress-strain curves of SLM3161 stainless steel samples with different process parameters to illustrate further the constitutive model's applicability for describing the dynamic mechanical properties of SLM elastoplastic materials.

This study can provide methodological support for the design and development of SLM mechanical parts. However, this study only analyzes the relationship between high strain rate and dynamic mechanical properties, which cannot accurately describe complex service conditions. Therefore, the study of the relationship between temperature 
and dynamic mechanical properties of SLM3161 stainless steel and the analysis of the J-C model with temperature terms are important to improve the design and development of the product.

\section{Acknowledgments}

This research was funded by the Anhui Education Department Top-Notch Talents Academic Funding Project (No.GxbjZD2020078), the Natural Science Foundation of Anhui Province (No.1708085ME130), the Anhui Education Department Excellent Young Talent Support Project (No.GxyqZD2019057), and the Supported by Hefei Municipal Natural Science Foundation (No.2021019).

\section{Date Availability}

The data that support the findings of this study are available within the article.

\section{Conflicts of interest}

The authors declare that there is no conflict of interest regarding the publication of this paper.

\section{References}

[1] Luo S, Su Y, Wang Z, et al. Tailored microstructures and strengthening mechanisms in an additively manufactured dual-phase high-entropy alloy via selective laser melting[J]. China Mater. 2020, 63(7), 1279-1290.

[2] Wang D, Yang Y Q, Liu R C.et al. Study on the designing rules and processability of porous structure based on selective laser melting (SLM) [J]. JOURNAL OF MATERIALS PROCESSING TECHNOLOGY. 2013,214, 1734-1742.

[3] Long T, Zhang X, Huang Q. Novel Mg-based alloys by selective laser melting for biomedical applications: microstructure evolution, microhardness and in vitro degradation behavior [J]. Virtual and Physical Prototyping. $2018,13,71-81$.

[4] Yin Y, Huang Q, Liang L.et al. In vitro degradation behavior and cytocompatibility of ZK30/bioactive glass composites fabricated by selective laser melting for biomedical applications[J]. Journal of Alloys and Compounds. 2019, 785, 38-45.

[5] Wu H, Liang L, Zeng H. et al. Microstructure and nanomechanical properties of Zr-based bulk metallic glass composites fabricated by laser rapid prototyping[J]. Materials Science and Engineering: A. 2019, 765, 138306.

[6] Zhang Y F, Majeed A, Muzamil M, et al. Investigation for macro mechanical behavior explicitly for thin-walled parts of AlSi10Mg alloy using selective laser melting technique[J]. JOURNAL OF MANUFACTURING PROCESSES. 2021,66(269-280).

[7] Xue J Q, Feng Z, Tang J G, et al. Selective laser melting additive manufacturing of tungsten with niobium alloying: Microstructure and suppression mechanism of microcracks[J]. JOURNAL OF ALLOYS AND COMPOUNDS.2021,874(159879).

[8] Chen J W, Zhang C H, Zhou F Q, et al. Microstructural, electrochemical and wear-corrosion characterization of TC4-5Cu alloy fabricated by selective laser melting[J]. JOURNAL OF ALLOYS AND COMPOUNDS.2021, 874(159953). 
[9] Wang C, Lin X, Wang L. et al. Cryogenic mechanical properties of 316L stainless steel fabricated by selective laser melting[J]. Materials Science and Engineering: A. 2021, 815, 141317.

[10] Wang D, Song C, Yang Y. et al. Investigation of crystal growth mechanism during selective laser melting and mechanical property characterization of 316L stainless steel parts[J]. Materials \& Design. 2016, 100, 291-299.

[11] Bang G B, Kim W R, Kim H K, Park H K, Kim G H, Hyun S K, Kwon O, Kim H G. Effect of process parameters for selective laser melting with SUS316L on mechanical and microstructural properties with variation in chemical composition[J]. Materials \& Design,2021,197.

[12] Cherry J A, Davies H. M, Mehmood S, Lavery N P, Brown S G R, Sienz J. Investigation into the effect of process parameters on microstructural and physical properties of 316L stainless steel parts by selective laser melting[J]. The International Journal of Advanced Manufacturing Technology,2015,76(5-8).

[13] Huang M J, Zhang Z X, Chen P. Effect of selective laser melting process parameters on microstructure and mechanical properties of $316 \mathrm{~L}$ stainless steel helical micro-diameter spring[J]. The International Journal of Advanced Manufacturing Technology, 2019, 104(5-8): 2117-2131.

[14] Tomasz K; Konrad G; Wojciech S; Bogumila K; Edward C. Correlation between process parameters, microstructure and properties of $316 \mathrm{~L}$ stainless steel processed by selective laser melting[J]. Materials Science \& Engineering A, 2018, 718: 64-73.

[15] Zhou T, J. Wu Z. Liang J. Che Y. Zhang X. Wang. A novel constitutive model for Ti-6Al-4V alloy based on dislocation pile-up theory. Materials Science and Technology. 2017,33 (11),1379-1387.

[16] Zhu S, Liu J, Deng X. Modification of strain rate strengthening coefficient for Johnson-Cook constitutive model of Ti6A14V alloy. Materials Today Communications.2021(26):102016.

[17] Seo, Jun-Min and Jeong, Sang-Seop and Kim, Yang and Kim, Jin and Oh, Chang-Young and Tokunaga, Hayato and Kumagai, Tomohisa and Miura, Naoki. Modification of the Johnson-cook Model for the Strain Rate Effect on Tensile Properties of 304/316 Austenitic Stainless Steels. Journal of Pressure Vessel Technology.2021(04).

[18] Fu Q, Xie Y, Long G, et al. Impact characterization and modelling of cement and asphalt mortar based on SHPB experiments[J]. International Journal of Impact Engineering, 2017, 106:44-52.

[19] Xie Y J, Qiang F, Zheng K R, et al. Dynamic mechanical properties of cement and asphalt mortar based on SHPB test[J]. Construction \& Building Materials, 2014, 70:217-225.

[20] Shin W S, Son, B, Song W S, et al. Heat treatment effect on the microstructure, mechanical properties, and wear behaviors of stainless steel 316L prepared via selective laser melting[J]. MATERIALS SCIENCE AND ENGINEERING A. 2021,806, 140805.

[21] P.F. Jiang, C.H. Zhang, S. Zhang, J.B. Zhang, J. Chen, H.T. Chen. Additive manufacturing of novel ferritic stainless steel by selective laser melting: Role of laser scanning speed on the formability, microstructure and properties. Optics \& Laser Technology. 2021(140), 107055.

[22] Zhao S, Li S J, Wang S G, et al. Compressive and fatigue behavior of functionally graded Ti-6Al-4V meshes fabricated by electron beam melting[J]. Acta Materialia, 2018 150, Pages 1-15.

[23] XIAO X, PAN H, BAI Y, et al. Application of the modified Mohr-Coulomb fracture criterion in predicting the ballistic resistance of 2024-T351 aluminum alloy plates impacted by blunt projectiles[J]. International Journal of Impact Engineering, 2019, 123: 26-37.

[24] WEI Gang, ZHANG Wie, HUANG Wie, et al. Effect of strength and ductility on deformation and fracture of 
three kinds of aluminum alloys during Taylor tests[J]. International Journal of Impact Engineering, 2014, 73: 75-90.

[25] Coper G R, Symonds P S. Strain-hardening and strain-rate effects in the impact loading of cantilever beams[R]. Providence: Brown University, 1957.

[26] Zhao W, Ye J, Qian J. Dynamic behavior and damage mechanisms of reinforced concrete piers subjected to truck impact[J]. Engineering Failure Analysis, 2020, 121:105158.

[27] Hwa C, Jha B, Yl A, et al. Experimental and numerical study on impact behavior of beam-column substructures of steel frame - Science Direct [J]. Structures, 2021, 29:14-29. 